\title{
PENGARUH FREE CASH FLOW DAN NET PROFIT MARGIN TERHADAP DIVIDEND PAYOUT RATIO PADA PERUSAHAAN MANUFAKTUR DI BURSA EFEK INDONESIA
}

\author{
Neni Marlina Br. Purba ${ }^{1 \text { )* }}$, Rio Rahmat Yusran ${ }^{2)}$ \\ ${ }^{1}$ Fakultas Ilmu Sosial dan Humaniora, Universitas Putera Batam \\ email: neni.marlina@puterabatam.ac.id \\ ${ }^{2}$ Fakultas Ilmu Sosial dan Humaniora, Universitas Putera Batam \\ email: rio@puterabatam.ac.id
}

\begin{abstract}
This study aims to determine the effect of free cash flow and net profit margins on dividend payout ratios in food and beverage sub-sector manufacturing companies listed on the Indonesia Stock Exchange in the period 2014-2018. The sampling method is done by purposive sampling method that is sampling using certain criteria. Hypothesis testing is carried out in this study with multiple linear regression tests, classic assumptions, partial tests, simultaneous tests and tests of determination. Based on the results of the partial analysis test that has been obtained obtained partially free cash flow does not have a significant effect on the dividend payout ratio. While the net profit margin partially has a significant effect on the dividend payout ratio. Based on the results of the analysis test simultaneously obtained simultaneously free cash flow and net profit margin affect the dividend payout ratio. For the determination test, the adjusted $R$ square value is 0.168 , which means that free cash flow and net profit margin have an effect of $16.8 \%$ on the dividend payout ratio and the remaining $83.2 \%$ is influenced by other variables not included in this study.
\end{abstract}

Keywords: Dividend Payout Ratio; Free Cash Flow; Net Profit Margin.

\begin{abstract}
ABSTRAK
Penelitian ini bertujuan untuk mengetahui pengaruh free cash flow dan net profit margin terhadap dividen payout ratio pada perusahaan manufaktur subsektor makanan dan minuman yang terdaftar pada Bursa Efek Indonesia pada periode 2014-2018. Metode pengambilan sampel dilakukan dengan teknik purposive sampling yaitu pengambilan sampel dengan menggunakan kriteria tertentu. Pengujian hipotesis yang dilakukan dalam penelitian ini dengan uji regresi linier berganda, asumsi klasik, uji parsial, uji simultan dan uji determinasi. Berdasarkan hasil uji analisis parsial yang telah dilakukan diperoleh yang diperoleh free cash flow secara parsial tidak berpengaruh signifikan terhadap dividend payout ratio Sedangkan net profit margin secara parsial berpengaruh signifikan terhadap dividend payout ratio. Berdasarkan hasil uji analisis secara simultan diperoleh free cash flow dan net profit margin secara simultan berpengaruh signifikan terhadap dividend payout ratio. Uji determinasi diperoleh nilai adjusted $R$ square sebesar 0.168, yang berarti free cash flow dan net profit margin memberikan pengaruh sebesar $16.8 \%$ terhadap dividend payout ratio dan sisanya sebesar $83.2 \%$ di pengaruhi oleh variabel lain yang tidak terdapat dalam penelitian ini.
\end{abstract}

Kata Kunci: Dividend Payout Ratio; Free Cash Flow; Net Profit Margin. 


\section{PENDAHULAN}

Pemegang menginvestasikan modal pada suatu perusahaan sangat mengharapkan tingkat pengembalian investasi atau pendapatan baik itu dividen ataupun capital gain. Dividen adalah keuntungan perusahaan yang diberikan kepada para pemilik, baik bentuk saham ataupun kas (Aristantia \& Putra, 2015). Dividen dalam bentuk tunai (kas) lebih dikehendaki oleh para penanam saham karena tunai menandakan kepastian laba yang langsung diterima tanpa harus mempertimbangkan profitabilitas perusahaan masa yang akan datang.

Pembagian dividen adalah pemberian laba kepada para pemilik menurut persentase saham yang dimiliki di perusahaan (Lioew, Murni, \& Mandagie, 2014). Berdasarkan kebijakan tersebut maka akan menyebabkan berkurangnya laba dan kas perusahaan, tetapi pemberian keuntungan kepada para penanam saham juga tujuan dari suatu bisnis. Jika deviden yang dibagikan bernilai besar, maka akan menguntungkan investor tetapi investasi perusahaan yang berkurang sehingga dapat mengurangi operasional dan tingkat pertumbuhan perusahaan sehingga pada akhirnya harga saham perusahaan akan menurun (Safrida, 2014).

Rasio dari keuntungan yang diperoleh kemudian akan dibagi kepada para investor disebut Dividend Payout Ratio (DPR). Seorang manajer harus bisa mengatur pengeluaran kas secara efektif dan efesien terutama pengeluaran dalam pemberian dividen kepada para pemegang saham dan pengeluaran untuk kebutuhan seluruh operasional perusahaan. Dengan kebijakan manajer yang tepat dalam pemberian dividen akan mempengaruhi nilai perusahaan, harga saham, serta keberlanjutan perusahaan untuk jangka panjang (Putri \& Putra, 2017).

Berikut ini nilai pembagian dividend payout ratio kepada para penanam modal yang mewakili perusahaan subsektor makanan dan minuman 3 tahun terakhir:

Tabel 1. Dividen Payout Ratio (\%)

\begin{tabular}{|l|l|l|l|l|}
\hline \multirow{2}{*}{ No. } & \multirow{2}{*}{$\begin{array}{c}\text { Kode } \\
\end{array}$} & Perusahaan & \multicolumn{3}{|c|}{ Tahun } \\
\cline { 3 - 5 } & 2016 & 2017 & 2018 \\
\hline 1 & ICBP & 24.94 & 49.76 & 19.41 \\
\hline 2 & INDF & 49.79 & 49.92 & 20.24 \\
\hline 3 & SKLT & 16.74 & 20.93 & 21.88 \\
\hline
\end{tabular}

Sumber: www.idx.co.id

Bersumber pada tabel 1 dapat dijelaskan bahwa perusahaan ICBP membagikan dividen terhadap investor pada tahun 2016 sebesar $24.94 \%$ dan pada tahun 2017 pembagian dividen meningkat menjadi $49.76 \%$ tetapi pada tahun 2018 pembagian dividen menurun menjadi $19.41 \%$. Begitu juga dengan perusahaan INDF, pada tahun 2016, dividen dibagikan kepada para investor sebesar $49.72 \%$ dan pada tahun 2017 juga mengalami peningkatan walapun sedikit yaitu sebesar 49.92\%. tetapi pada tahun 2018 mengalami penurunan drastis menjadi $20.24 \%$.

Fluktuasi nilai dividen yang diberikan kepada para investor dapat menyebabkan keraguan para investor dalam menanamkan saham mereka. Karena para investor akan lebih merasa tenang apabila mendapatkan dividen meningkat setiap tahunnya walapun tidak terlalu signifikan kenaikan yang mereka peroleh. Besar kecilnya pembagian dividen terhadap investor juga sangat berdampak pada kelanjutan operasional perusahaan. Semakin sedikit dividen yang dibagikan, maka ketertarikan para investor terhadap perusahaan juga semakin kecil. Dan sebaliknya, semakin banyak dividen yang diberikan kepada para investor maka aliran kas bebas perusahaan akan semakin kecil (Lucyanda \& Lilyana, 2012).

Berbeda dengan perusahaan SKLT, perusahaan ini memerikan dividen meningkat setiap tahunnya yaitu pada tahun 2016 sebesar $16.74 \%$ dan meningkat pada tahun 2017 menjadi $20.93 \%$ dan terakhir pada tahun 2018 sebesar $21.88 \%$. 
Tetapi peningkatan pemberian dividen terhadap investor juga akan menurunkan nilai arus kas bebas perusahaan.

Selain arus kas bebas perusahaan, profitabilitas yang perusahaan juga akan mempengaruhi besar kecilnya pemberian dividen kepada para investor. Karena semakin tinggi profitabilitas yang diperoleh perusahaan, maka para investor juga akan mengharapkan nilai deviden yang lebih besar pula (Hutami, 2012). Dan sebaliknya, semakin kecil nilai keuntungan yang diperoleh dari aktivitas perusahaan, maka para pemberi modal juga akan menurun minatnya untuk menaruh uang mereka pada perusahaan tersebut.

Bersumber dari beberapa persoalan yang sudah dijelaskan diatas maka penelitian ini bertujuan untuk mengetahui seberapa besar dampak yang dapat tejadi dari free cash flow dan net profit margin terhadap dividend payout ratio.

\section{KAJIAN LITERATUR}

\subsection{Dividend Payout Ratio}

Besarnya persentase dividen yang akan dibagikan kepada para pemegang saham dapat mewakili oleh sebuah rasio yang biasa kita kenal dengan rasio pembayaran dividen. Rasio ini adalah persentase dari pendapatan setelah pajak yang berubah menjadi dividen. Rasio pembayaran dividen (Dividend Payout Ratio) merupakan rasio yang mengukur perbandingan dividen terhadap laba perusahaan (Lioew et al., 2014). Misalnya, jika perusahaan berhasil meraih laba bersih antara Rp100 miliar hingga Rp125 miliar maka perusahaan akan memberikan dividen sebanyak 20 persen dari laba bersih. Jika laba bersih yang dicapai antara Rp125 miliar hingga Rp150 miliar maka nilai dividen yang akan dibagi adalah 25 persen dari laba bersih. Setiap emiten memiliki formula berbeda-beda dalam menentukan dividend payout ratio(Suherman, Lukman, \& Kusnadi, 2015).

Peraturan pembagian dividen yaitu rencana yang melibatkan dua kelompok kepentingan yang berbeda yakni pemegang saham dan manajemen perusahaan. Kedua kelompok ini menanggapi dividen dengan keperluan masing-masing. Dari segi pemegang saham mempertimbangkan dividen sebagai bentuk kompensasi atau kepemilikan terhadap saham perusahaan. Sebaliknya pihak manajemen menganggap dividen sebagai pengurangan potensial laba ditahan (Rahmawati, Saerang, \& Rate, 2014).

Nilai rasio pemberian dividen kepada para penanam modal akan memberikan dampak terhadap jumlah laba yang akan ditahan perusahaan untuk sumber pergerakan perusahaan (Rahmawati et al., 2014). Akan tetapi, jika laba yang ditahan perusahaan dalam jumlah yang besar, maka para penerima dividen yaitu investor akan mendapatkan dividen dengan nominal kecil sehingga para investor akan beranggapan bahwa perusahaan tidak bergerak dengan baik.

\subsection{Free Cash Flow}

Arus Kas Bebas (free cash flow) merupakan kebutuhan yang sangat penting yang dimiliki sebuah perusahaan, karena semakin besarnya arus kas bebas perusahaan maka perusahaan dapat menunjukkan kepada para pemegang saham bahwa posisi perusahaan dalam keadaan baik (Aristantia \& Putra, 2015).

Arus kas bebas juga dapat diartikan sebagai nilai akhir kas dari perhitungan arus kas yang diperoleh oleh suatu perusahaan di akhir suatu periode keuangan (kuartalan atau tahunan) setelah perusahaan membayar semua kewajibannya seperti membayar gaji, biaya produksi, tagihan, cicilan hutang berikut bunganya, pajak, dan juga belanja modal (capital expenditure) untuk pengembangan usaha. Sisa uang setelah pembayaran semua kewajiban perusahaan inilah yang disebut arus kas bebas (Putri \& Putra, 2017)

Arus Kas Bebas merupakan kas yang terdapat pada perusahaan yang dapat 
digunakan untuk berbagai aktivitas (Muhardi, 2013). Free cash flow juga sangat penting bagi perusahaan untuk dapat memungkinkan perusahaan sehingga dapat mensejahterakan pemegang saham. Arus kas bebas juga dapat diartikan sebagai arus kas yang memang tersedia untuk dibagikan kepada para investor (pemegang saham dan pemilik utang) setelah perusahaan melakukan investasi dalam aset tetap, produk baru, dan modal kerja yang dibutuhkan untuk mempertahankan operasi yang sedang berjalan (F.Brigham \& Houston, 2012)

\subsection{Net Profit Margin}

Kesanggupan dalam membuahkan laba ialah salah satu dari tingkat penjualan yaitu net profit margin (NPM). Rasio ini adalah salah satu dari rasio profitabilitas (Lopolusi, 2013). Net profit margin (margin laba bersih) adalah jumlah rasio dari setiap hasil penjualan setelah dikurangi seluruh biaya dan pengeluaran, termasuk bunga dan pajak (Rudianto, 2013). Net profit margin adalah rasio yang memperkirakan sepanjang kinerja perusahaan untuk membuahkan laba bersih pada tingkat penjualan tertentu (Egam, Ilat, \& Pangerapan, 2017). Rasio net profit margin juga dapat ditafsirkan sebagai aktivitas perusahaan dalam meminimkan semua pengeluaran diperusahaan pada waktu tertentu.

Net profit margin yang kecil melambangkan penjualan perusahaan besar dalam tingkat pengeluaran tertentu, atau pengeluaran yang terlalu tinggi untuk tingkat penjualan yang tertentu, atau gabungan dari kedua hal tersebut. Efisiensi suatu perusahaan dapat dipandang dari kesiapan perusahaan menghemat rasio penggunaan dana pengeluaran perusahaan. Apabila perusahaan tecapai menghemat pengeluaran bagi kegiatan operasional dan finansial, maka bagian laba bersih yang buat perusahaan atas penjualan yang dilakukannya menjadi lebih besar (Rahmawati et al., 2014). Salah satu indikator efisien tidaknya suatu perusahaan dapat dilihat dari margin laba bersih, sehingga dipercaya semakin tinggi NPM yang dihasilkan maka perusahaan akan semakin baik (Muhardi, 2013).

\section{METODE PENELITIAN}

Metode dalam penelitian ini melalui metode kuantitatif. Variabel dalam riset ini memakai variabel dependen yakni dividen payout ratio sedangkan variabel independen yaitu free cash flow dan net profit margin. Populasi dalam riset ini seluruh perusahaan subsektor makanan dan minuman yang terdaftar di Bursa Efek Indonesia tahun 2014 - 2018. Pengambilan sampel dengan cara purposive sampling (Sugiyono, 2012). Data yang dipakai berupa data yang sudah ada seperti laporan keuangan yang diunduh melalui website resmi Bursa Efek Indonesia yaitu www.idx.co.id.

Pemeriksaan hipotesis didukung dengan SPSS. Teknik analisis data memakai cara analisis statistik deskriptif, asumsi klasik (uji normalitas, uji multikolinieritas, uji heterokedastisitas dan uji autokorelasi). Riset ini menggunakan analisis regresi linier berganda. Sedangkan uji hipotesis yang dipakai yakni uji parsial, uji simultan dan uji koefisien determinasi (Ghozali, 2013).

\section{HASIL DAN PEMBAHASAN}

\subsection{Hasil Penelitian}

1. Hasil Analisis Deskriptif

Hasil uji analisis deskriptif yang dihasilkan dalam penelitian ini dapat diperhatikan pada tabel 2 berikut ini:

Tabel 2. Analisis Statistik Deskriptif

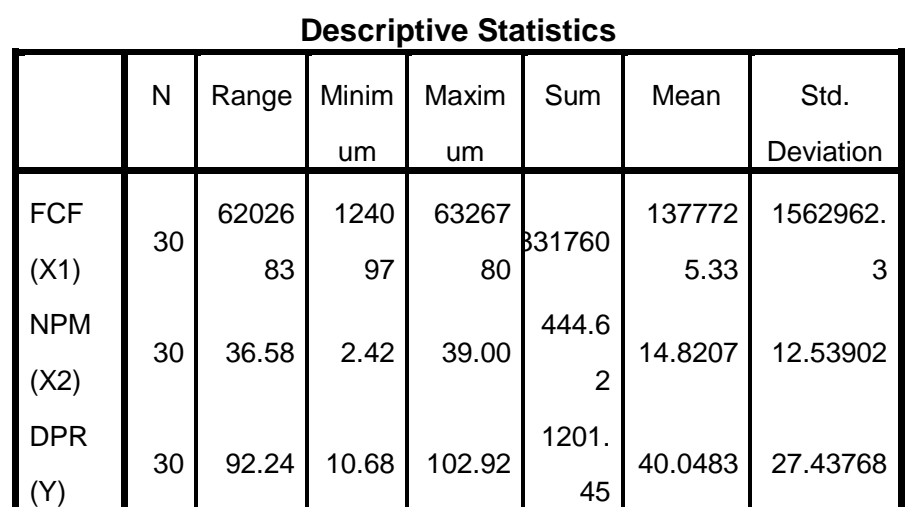


Sumber: Olah Data SPSS 20

Hasil dari tabel 2 memperlihatkan sampel penelitian ini sebanyak 30 dan semua nilai minimum, maksimum, mean dan standar deviasi setiap variabel penelitian dapat diamati dengan jelas pada tabel 2. Fee cash flow memiliki nilai minimum 124097, nilai maksimum 6326780 , mean atau rata-rata 1377725.33 dan nilai standar deviasinya 1562962.3. Net profit margin memiliki nilai minimum 2.42, nilai maximum 39.00, mean 14.8207 dan standar deviasi 12.53902. Sedangkan Dividen payout ratio (DPR) memiliki nilai minimum 10.68, nilai maksimum 102.92, Mean atau rata-rata 40.0483 dan nilai standar deviasinya 27.43768 .

\section{Hasil Uji Normalitas}

Pengujian ini nantinya akan di pakai dalam regresi, untuk melihat data yang dipakai harus memiliki data yang normal.

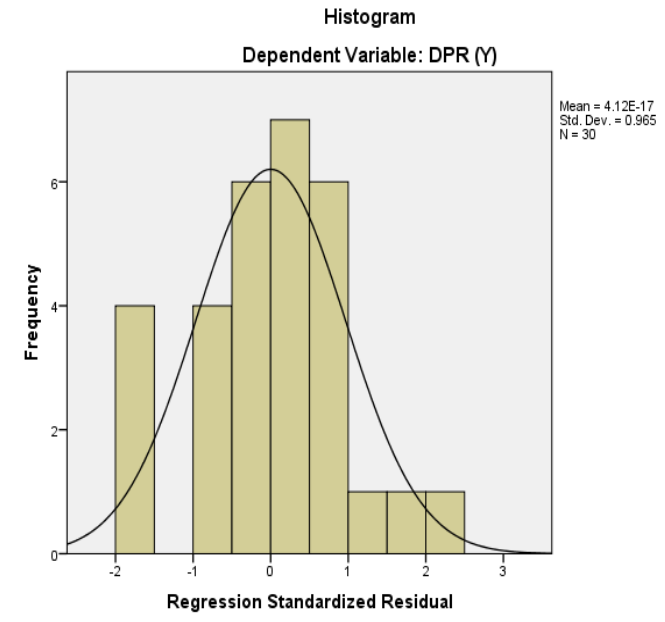

Gambar 1. Bell Shaped Curve

Sumber: Olah Data SPSS 20

Hasil gambar 1 diatas tampak bahwa model kurva yang seakan-akan seperti lonceng sempurna yang berarti keseluruhan data yang digunakan berdistribusi normal.

\section{Hasil Uji Multikolinieritas}

Penilaian baik atau tidaknya regresi dari segi multikolenearitas yaitu penelitian dikatakan baik jika tidak adanya hubungan
Tabel 3. Hasil Uji Multikolinearitas

\begin{tabular}{|c|c|c|c|}
\hline \multirow{2}{*}{\multicolumn{2}{|c|}{ Model }} & \multicolumn{2}{|c|}{ Collinearity Statistics } \\
\hline & & Tolerance & VIF \\
\hline \multirow{3}{*}{1} & (Constant) & & \\
\hline & $\mathrm{FCF}(\mathrm{X} 1)$ & .921 & 1.085 \\
\hline & NPM (X2) & .921 & 1.085 \\
\hline
\end{tabular}

Setelah diamati melalui tabel 3, hasil uji multikolinearitas dapat dikatakan tidak terjadi multikolinearitas antar sesama variabel bebas hal ini dikarenakan angka VIF dari free cash flow $1.085<10$, dan net profit margin $1.085<10$. Sedangkan jika kita bandingkan dari nilai tolerance, nilai tolerance free cash flow 0.921, dan net profit margin 0,921. Dari nlai yang diperoleh, seluruh nilai tolerance variabel bebas diatas 0,1 .

\section{Hasil uji heterokedastisitas}

Pengujian gejala heteroskedastisitas dipakai agar dapat memberikan informasi tentang ada atau tidak ikatan antara variabel pengancam dengan variabel bebasnya.

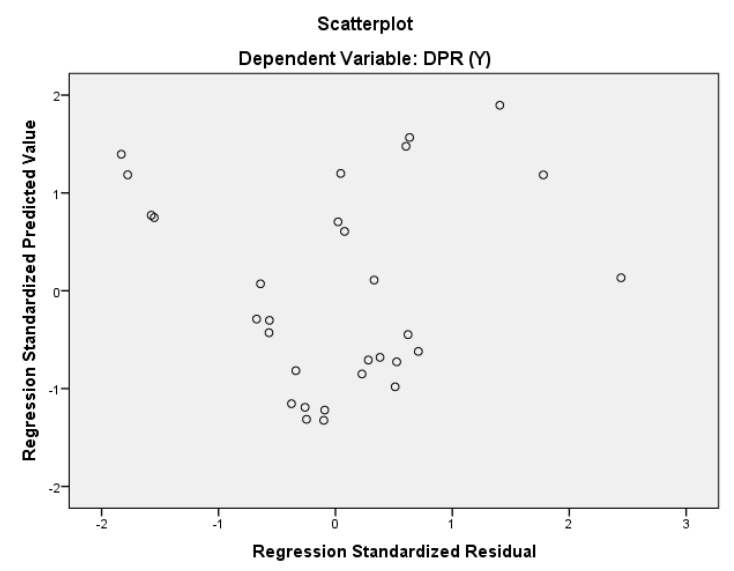

Gambar 2. Scatterplot

Sumber: Olah Data SPSS 20 
Pengujian hasil heteroskedastisitas memakai scatterplot. Hasilnya dapat diamati dalam gambar 2, dimana tampak bahwa data memencar sembarang serta tersebar didaerah angka 0 pada koordinat sumbu Y. Maka dapat ditetapkan bahwa heteroskedastisitas tidak berlaku pada regresi tersebut.

5. Hasil uji autokorelasi

Pengujian ini untuk mengetahui korelasi antar serial data atau antar data sebelum dengan data setelahnya. Data yang baik ialah data yang tidak terdeteksi autokorelasi (Sujarweni, 2016:231).

Tabel 4. Hasil Uji Autokorelasi Model Summary ${ }^{\mathrm{b}}$

\begin{tabular}{|l|c|r|r|r|}
\hline Model & $\mathrm{R}$ & $\begin{array}{c}\mathrm{R} \\
\text { Square }\end{array}$ & $\begin{array}{c}\text { Adjusted } \\
\text { R Square }\end{array}$ & $\begin{array}{c}\text { Durbin- } \\
\text { Watson }\end{array}$ \\
\hline 1 & $.475^{\mathrm{a}}$ & .225 & .168 & 1.728 \\
\hline
\end{tabular}

a. Predictors: (Constant), NPM (X2), FCF (X1)

b. Dependent Variable: DPR (Y)

Sumber: Data Olahan SPSS 20

Hasil amatan tabel 4 terdapat angka Durbin Watson (DW) 1.728 dan nilai du yang dihasilkan dari tabel statistik Durbin Watson dengan $\mathrm{k}=3$ dan $\mathrm{n}=30$ maka nilai du $=1.6498$, dan $4-\mathrm{du}=4-1.6498$ $=2.3502$, sehingga melengkapi persamaan $\mathrm{du}<\mathrm{dw}<4$ - du yakni $1.6498<1.728<$ 2.3502 ini menandakan tidak terdeteksi adanya autokorelasi.

6. Regresi linier berganda

Tabel 5. Analisis Regresi Linier Berganda

\begin{tabular}{|c|c|c|}
\hline \multirow[t]{2}{*}{ Model } & \multicolumn{2}{|c|}{$\begin{array}{c}\text { Unstandardized } \\
\text { Coefficients }\end{array}$} \\
\hline & $B$ & Std. Error \\
\hline (Constant) & 19.481 & 9.248 \\
\hline 1 FCF $(X 1)$ & 3.360E-006 & .000 \\
\hline NPM (X2) & 1.075 & .386 \\
\hline
\end{tabular}

Sumber: Olah Data SPSS

Hasil yang diperoleh pada regresi linier berganda tersaji melalui tabel 5 , sehingga dapat diambil rumus dari persamaan regresi linier berganda adalah sebagai berikut:

$\mathrm{Y}=19.481+3.360 \mathrm{E}-006 \mathrm{X} 1+1.075 \mathrm{X} 2$
7. Hasil uji parsial

Uji parsial dipakai untuk melihat pembuktian tentang sejauhmana variabel terikat dipengaruhi oleh variabel bebas secara mandiri atau individu.

Tabel 6. Hasil Uji Parsial

\begin{tabular}{|l|r|r|}
\hline \multicolumn{1}{l|}{ Model } & \multicolumn{1}{c|}{$\mathrm{t}$} & \multicolumn{1}{l|}{ Sig. } \\
\hline (Constant) & 2.106 & .045 \\
1 FCF (X1) & 1.085 & .288 \\
NPM (X2) & 2.785 & .010 \\
\hline
\end{tabular}

Sumber: Olah Data SPSS 20

Dari hasil tabel 6 dapat diamati bahwa bilangan signifikat free cash flow 0.288 , dimana angka tersebut diatas 0.05 dan bilangan $\mathrm{t}$ hitung 1.085 dibawah dari angka $\mathrm{t}$ tabel 2.05183. Dapat diambil keputusan bahwa free cash flow tidak ada memberikan dampak yang signifikan terhadap dividend payout ratio.

Selain itu, bilangan signifikan net profit margin 0.10, dan angka tersebut dibawah dari 0.05 dan $\mathrm{t}$ hitung 2.785 lebih besar dari 2.05183. Maka, ketetapan yang diambil bahwa net profit margin memberikan dampak yang signifikan terhadap dividend payout ratio.

\section{Hasil uji simultan}

Uji simultan dipakai dalam pengujian signifikansi untuk melihat sejauhmana dampak yang dapat diberikan variabel indenpenden terhadap variabel dependen secara serentak.

Tabel 7. Hasil Uji Simultan

\begin{tabular}{|ll|c|c|}
\hline \multicolumn{2}{|l|}{ Model } & F & Sig. \\
\hline & $\begin{array}{l}\text { Regression } \\
1\end{array}$ & 3.929 & $.032^{\mathrm{b}}$ \\
& $\begin{array}{l}\text { Residual } \\
\text { Total }\end{array}$ & & \\
\hline
\end{tabular}

Sumber: Olah Data SPSS

Melalui tabel 7 yang telah tersaji diatas, dapat diperhatikan bahwa angka signifikan 
0.032, dimana angka tersebut dibawah 0.05 . Begitu pula angka yang didapatkan pada f hitung 3.929 lebih besar dari f tabel 0,032, maka keputusan yang diterima free cash flow dan net profit margin secara serentak berdampak signifikan terhadap dividend payout ratio.

9. Hasil uji koefisien determinasi $\left(\mathrm{R}^{2}\right)$

Uji koefisien determinasi $\left(\mathrm{R}^{2}\right)$ diperuntukkan dalam menghitung besar kecil rasio atas dampak yang diterima oleh variabel terikat dari variabel bebas.

Tabel 8. Koefisien Determinasi Model Summary

\begin{tabular}{|l|r|r|r|}
\hline $\begin{array}{l}\text { Mode } \\
\mathrm{I}\end{array}$ & $\mathrm{R}$ & $\begin{array}{c}\mathrm{R} \\
\text { Square }\end{array}$ & \multicolumn{1}{c|}{$\begin{array}{c}\text { Adjusted R } \\
\text { Square }\end{array}$} \\
\hline 1 & $.475^{\mathrm{a}}$ & .225 & .168 \\
\hline
\end{tabular}

Sumber: Olah Data SPSS

Melalui tabel 8, angka yang dapat dilihat dari adjusted $R$ square sebesar 0.168, yang menandakan free cash flow dan net profit margin memberikan dampak sebesar $16.8 \%$ terhadap dividend payout ratio dan selebihnya senilai $83.2 \%$ diberi dampak oleh variabel lain.

\subsection{Pembahasan}

1. Pengaruh Free Cash Flow terhadap Dividen Payout Ratio

Berdasakan serangkaian hasil uji yang sudah dijalankan hingga dikatakan free cash flow tidak memberikan dampak yang signifikan terhadap dividend payout ratio secara mandiri. Jika dipandang free cash flow bernilai positif, tetapi tidak berdampak signifikan kepada dividend payout ratio. Interpretasinya, sedikit banyaknya free cash flow yang dipunya perusahaan tidak merubah nilai pemberian dividend payout ratio yang dibagikan pada donatur saham. Hal tersebut terjadi karena pihak perusahaan meberlakukan pembayaran dividen yang konstan kepada para investor, sehingga walaupun free cash flow yang dipunyai perusahaan banyak ataupun sedikit maka hasil dividen yang diberikan perusahaan angkanya konstan.

Kesimpulan ini sepaham dengan penelitian (Raissa, 2012) yang menngatakan bahwa free cash flow tidak berpengaruh signifikan terhadap dividend payout ratio. Tetapi tidak sepaham dengan penelitian (Lucyanda \& Lilyana, 2012) yang menngatakan bahwa perusahaan yang mempunyai free cash flow yang tinggi cenderung membagikan dividen yang lebih banyak juga.

2. Pengaruh Net Profit Margin terhadap Dividen Payout Ratio

Dipandang dari keputusan uji parsial didapatkan bahwa net profit margin memberikan dampak signifikan terhadap dividend payout ratio. Net profit margin adalah rasio untuk menilai kinerja perusahaan untuk mendapatkan laba bersih dari penjualan.

Semakin besar skala net Profit Margin menanadakan baiknya kemampuan perusahaan dalam menciptakan laba bersih. Net profit Margin memberikan dampak signifikan terhadap devidend payout ratio. Implementasi ini menandakan ketika net profit margin bertambah maka deviden payout ratio akan meningkat sehingga ketika net profit margin perusahaan semakin stabil maka hal tersebut dapat menguntungkan pihak internal dan pihak eksternal perusahaan seperti investor.

Hasil ini searah dengan penelitian (Rahmawati et al., 2014) yang menghasilkan net profit margin memberi pengaruh signifikan terhadap devidend payout ratio. Tetapi bertolak arah dengan penelitian (Jalung, Magantar, \& Mandagie, 2017) yang menunjukkan net profit margin tidak berdampak signifikan terhadap devidend payout ratio.

3. Pengaruh Free Cash Flow dan Net Profit Margin terhadap Dividen Payout Ratio

Berdasarkan pengujian secara simultan didapatkan bahwa free cash flow dan net 
profit margin secara serentak memberikan dampak yang signifikan kepada dividend payout ratio. Ini menandakan semakin banyak aliran kas bebas yang didapat perusahaan dan semakin meningkat net profit margin yang dihasilkan perusahaan berarti pembagian keuntungan kepada para pihak eksternal juga akan semakin besar. Semakin besar dividen yang diperoleh para investor, maka investor akan semakin percaya terhadap perusahaan dalam mengelola modal yang mereka tanamkan.

\section{SIMPULAN DAN SARAN}

\subsection{Simpulan}

Berdasarkan hasil analisis dan pembahasan yang telah di lakukan, maka penelitian ini dapat di simpulkan sebagai berikut:

1. Free cash flow secara parsial tidak berpengaruh signifikan terhadap dividend payout ratio pada perusahaan manufaktur sub sektor makanan dan minuman yang terdaftar di Bursa Efek Indonesia.

2. Net profit margin secara parsial berpengaruh signifikan terhadap dividend payout ratio pada perusahaan manufaktur sub sektor makanan dan minuman yang terdaftar di Bursa Efek Indonesia.

3. Secara simultan free cash flow dan net profit margin berpengaruh terhadap dividend payout ratio pada perusahaan manufaktur sub sektor makanan dan minuman yang terdaftar di Bursa Efek Indonesia.

4. Pada uji koefisien determinasi diperoleh nilai adjusted $\mathrm{R}$ square sebesar 0.168 yang menunjukkan bahwa free cash flow dan net profit margin memberikan pengaruh terhadap dividend payout ratio sebesar $16.8 \%$ dan sisanya sebesar $83.2 \%$ di pengaruhi oleh variabel lain yang tidak terdapat dalam penelitian ini.

\subsection{Saran}

Agar penelitian ini dapat lebih berkembang luas dan lebih mendalam, maka berikut ini beberapa saran dari peneliti:

1. Disarankan bagi para perusahaan untuk meningkatkan Net Profit Margin (NPM) agar Dividend Payout Ratio (DPR) yang diperoleh investor semakin tinggi, karena jika investor memperoleh DPR yang tinggi maka minat investor untuk menanam saham akan semakin meningkat.

2. Bagi peneliti selanjutnya disarankan agar dapat menambah variabel independen penelitian, meneliti dengan objek yang berbeda sehingga penelitian selanjutnya kan lebih melengkapi penelitian ini.

\section{UCAPAN TERIMAKASIH}

Ucapan terima kasih terutama ditujukan kepada Universitas Putera Batam dan LPPM yang telah membantu dalam pelaksanaan penelitian ini sehingga penelitian ini dapat berjalan dengan sebagaimana mestinya.

\section{DAFTAR PUSTAKA}

Aristantia, D., \& Putra, I. M. P. D. (2015). Investment Opportunity Set Dan Free Cash Flow Pada Tingkat Pembayaran Dividen Perusahaan Manufaktur. EJurnal Akuntansi Universitas Udayana, 1(11), 220-234.

Egam, G. E. Y., Ilat, V., \& Pangerapan, S. (2017). Pengaruh Return On Asset (Roa), Return On Equity (Roe), Net Profit Margin (Npm), Dan Earning Per Share (Eps) Terhadap Harga Saham Perusahaan Yang Tergabung Dalam Indeks Lq45 Di Bursa Efek Indonesia Periode Tahun 2013-2015. Jurnal EMBA, 5(1), 105-114.

F.Brigham, E., \& Houston, J. F. (2012). Dasar-Dasar Manajemen Keuangan (Edisi Kedu). Jakarta: Salemba Empat.

Ghozali, I. (2013). Aplikasi Analisis 
Multivariate Dengan Program IBM SPSS 21. Semarang: Badan Penerbit Universitas Ponogoro.

Hutami, R. P. (2012). Pengaruh Dividend Per Share, Return on Equity Dan Net Profit Margin Terhadap Harga Saham Perusahaaan Industri Manufaktur Yang Tercatat Di Bursa Efek Indonesia Periode 2006-2010. Jurnal Nominal, I(1), 105-123. Retrieved from www.idx.co.id

Jalung, K., Magantar, M., \& Mandagie, Y. (2017). Analisis Faktor-Faktor Yang Mempengaruhi Dividend Payout Ratio Pada Sub-Sektor Bank Yang Terdaftar Di Bursa Efek Indonesia. Jurnal EMBA, 5(2), 334-342.

Lioew, A. M., Murni, S., \& Mandagie, Y. (2014). ROA, ROE, NPM Pengaruhnya Terhadap Dividen Payout Ratio Pada Perusahaan Perbankan Dan Financial Institusi Yang Terdaftar Di Bei Periode 20102012. Jurnal EMBA, 2(2), 14061416.

Lopolusi, I. (2013). Analisis Faktor-faktor Yang Mempengaruhi Kebijakan Dividen Sektor Manufaktur Yang TerdafTar Di PT Bursa Efek Indonesia Periode 2007-2011. Jurnal Ilmiah Mahasiswa Universitas Surabaya, 2(1), 1-18. https://doi.org/10.1002/cbic.2008000 77

Lucyanda, J., \& Lilyana. (2012). Pengaruh Free Cash Flow Dan Struktur Kempemilikan Terhadap Dividen Payout Ratio. Jurnal Dinamika Akuntansi, 4(2), 129-138.

Muhardi, W. R. (2013). Analisis Laporan Keuangan: Proyeksi dan Valuasi Saham. Jakarta: Salemba Empat.

Putri, P. A. D., \& Putra, I. N. wijana A. (2017). Pengaruh Free Cash Flow Perusahaan Di Tahap Growth dan Mature Pada Kebijakan Dividen. EJurnal Akuntansi Universitas Udayana, 20(1), 87-115.

Rahmawati, N. D., Saerang, I. S., \& Rate, P. Van. (2014). Kinerja Keuangan
Pengaruhnya terhadap Kebijakan Dividen pada Perusahaan BUMN di Bursa Efek Indonesia. Jurnal EMBA, 2(2), 1306-1317.

Raissa, F. (2012). Faktor-Faktor yang Mempengaruhi Kebijakan Deviden Pada Perusahaan Industri Barang Konsumsi di Bursa Efek Indonesia. Jurnal Wima, 1(6), 10-28.

Rudianto. (2013). Pengantar Akuntansi Manajemen. Jakarta: Erlangga.

Safrida, E. (2014). Profitabilitas Dan Pertumbuhan Perusahaan Terhadap Kebijakan Deviden Pada Perusahaan Manufaktur Di Indonesia. Jurnal Riset Akuntansi Dan Keuangan, 2(1), 289.

https://doi.org/10.17509/jrak.v2i1.658 2

Sugiyono. (2012). Metode Penelitian Kuantitatif, Kualitiatif Dan $R \& D$. Bandung: Alfabet.

Suherman, R., Lukman, L., \& Kusnadi. (2015). Pengaruh Free Cash Flow, Hutang dan Tingkat Pertumbuhan Perusahaan Terhadap Kebijakan Deviden pada Perusahaan Manufaktur yang Terdaftar di Bursa Efek Indonesia. Jurnal Magister Manajemen, 1(2), 209-217.

Sujarweni, V. W. (2016). Kupas Tuntas PENELITIAN AKUNTANSI Dengan SPSS (lengkap; Mona, ed.). Yogyakarta: Penerbit Pustaka Baru Press. 